\title{
Better Thyroid Cytopathology Reporting System May Increase the Clinical Management and Patients Outcome
}

Mulazim Hussain Bukhari* ${ }^{1 *}$ Asad Aslam Khan², Shahida Niazi², Madiha Arshad ${ }^{2}$, Zahid Mahmood Akhtar ${ }^{2}$ and Khalid Ahmed AL-Sindi ${ }^{2}$

${ }^{1}$ Department of Pathology, King Edward Medical University, Lahore, Pakistan

${ }^{2}$ Department of Pathology, King Hamad University Hospital, Bahrain

\begin{abstract}
Objective: The Bethesda System is better for Thyroid Cytopathology reporting and may increase the clinical management of Thyroid Disease.

Study design: Analytical Cross sectional.

Material and methods: A cross sectional study was conducted on 120 smears of thyroid swellings which were referred for fine needle aspiration to the Department of Pathology in 2011 and the Bethesda System for reporting Thyroid Cytopathology was followed in comparison to old conventional reporting system running from the last 30 years. Histopathology was used as a gold standard to compare the sensitivity of both systems. Three groups of Histopathologists were assigned three reporting systems without knowing the results of each other. The comparison was made in a meeting of 3 groups after histopathology biopsy reports were made available. Group A was assigned to report with the older system of thyroid aspiration with 7 categories, Group B reported with five classes of an older reporting system and Group C reported with the latest Bethesda Reporting System. Screening test was applied to compare the results.

Results: When the results of these three systems were compared Bethesda adapted method was found to be more superior as compared to the others. Sensitivity of Group B and C is significantly high 0.051 as compared to group A ( $p=0.051$ and 0.000 )' Sensitivity of Group C is also significantly high as compared to Group B ( $p=0.000$ ). Specificity of Group B is not significant $(0.326)$ as compared to group A. Specificity of group C is also significantly high as compared to Group A and Group B ( $p=0.009$ and 0.002). Our findings are consistent with others who used the Bethesda Cytopathology Reporting System.
\end{abstract}

Conclusions: Bethesda Cytopathology Reporting system can help with a better patient's outcome due to proper clinical management of thyroid swellings and saves patients from unnecessary thyroid surgery.

Keywords: Thyroid gland swellings; FNAC; Thyroid cytopathology classification systems; Inadequate samples; Follicular lesions

\section{Introduction}

Palpable thyroid nodules may be found in $4-7 \%$ of the general population, and this prevalence may approach $60 \%$ when highresolution Ultrasonography (USG) is used [1-3]. Fine needle aspiration cytology is a well-established technique for preoperative investigation of thyroid nodules. The technique is a noninvasive, cost-effective, and efficient specific and an excellent cost-effective method in the investigation of solitary thyroid nodules $[4,5]$. Indeterminate results, like suspicious for malignancy and follicular neoplasm or lesion [6], variability in reporting systems [7], and inadequate specimens limit the utility of FNAC and may complicate the management of thyroid nodules $[8,9]$.

The history of Thyroid Fine Needle Aspiration Cytology (FNAC) at our institution is over 30 years old and reporting was modified with the passage of time [10]. The recent developments in the reporting system of Thyroid Fine Needle Aspiration Cytology (FNAC) is due to the need of the day because thyroid nodules are becoming more common day by day, however thyroid cancer is still comparatively rare [11].

"The literature shows wide variations in the criteria for inadequate thyroid FNAC and study of inclusion or exclusion criteria. Inclinic assessment of specimen adequacy and in-clinic reporting of thyroid FNAC has become popular although the costs and resource implications of in-clinic thyroid FNAC assessment and reporting are substantial" [12].
Standardized categorical systems for FNAC reporting can make results easier to understand for clinicians and give clear indications for therapeutic action $[12,13]$.

\section{Materials and Methods}

A cross sectional study was conducted on 120 smears of thyroid swellings which were sent for fine needle aspiration to the Department of Pathology in 2011 and the Bethesda System for reporting thyroid cytopathology was followed in comparison to the old conventional reporting system running for the last 30 years. Histopathology was used as a gold standard to compare the sensitivity of both systems.

Three groups of Histopathologists were assigned three reporting systems without knowing the results of each other. The comparison

*Corresponding author: Mulazim Hussain Bukhari, Department of Pathology, King Edward Medical University, Lahore, Pakistan, E-mail: drmhbukhari@yahoo.com

Received October 05, 2012; Accepted October 26, 2012; Published October 29 2012

Citation: Bukhari MH, Khan AA, Niazi S, Arshad M, Akhtar ZM, et al. (2012) Better Thyroid Cytopathology Reporting System May Increase the Clinical Management and Patients Outcome. J Cytol Histol 3:158. doi:10.4172/2157-7099.1000158

Copyright: @ 2012 Bukhari MH, et al. This is an open-access article distributed under the terms of the Creative Commons Attribution License, which permits unrestricted use, distribution, and reproduction in any medium, provided the original author and source are credited. 
was made in a meeting of the three groups after biopsy reports were made available.

\section{Inclusion criteria}

(1) Age 10 to 70 Years.

(2) Both genders.

(3) Patients presenting with thyroid swelling in any lobe of thyroid selected by clinical palpation (multinodular, solitary nodules, diffuse goiter etc).

(4) Patients with recurrent thyroid swellings after a previous thyroid surgery.

\section{Exclusion criteria}

(1) Patients with already diagnosed thyroid lesions.

(2) All toxic goiters confirmed by clinical evaluation and laboratory parameters.

All patients presenting with solitary thyroid nodules in the OPD and fulfilling the inclusion criteria were included in this study. Informed consent from all the patients included in the study was taken. All included patients were recorded for their demographic features, that is, age, sex, and address and telephone contacts (for follow up). History of present illness with regard to symptoms and duration was recorded. They were examined for signs related to the solitary thyroid swelling. All routine investigations and serum T3, T4, and TSH levels were performed by Radioimmunoassay (RIA), (normal range of T3, 2.5-5.8 nmol/L, T4, 11.5-23.0 nmol/L, and TSH, 0.2-4.0 $\mathrm{mIU} / \mathrm{L}$ ). Patients with thyroid swellings also underwent a thyroid scan. Thyroid swellings were marked through by the nuclear department and then FNAC was performed [12].

\section{Group A}

Was assigned to report with the conventional system according to which; Cytological diagnosis was categorized into the following 7 groups [10,12].

Nondiagnostic or Unsatisfactory: (when smears are hemorrhagic or containing less than six groups of well-preserved follicular cells on each of at least two slides.

Colloid goiter: When smears contained follicular cells with abundant thick colloid in the background.

Colloid cysts: When follicular cells, thin or thick colloid in the background and hemosiderin laden macrophages were seen in the smears.

Follicular lesions/Neoplasm: When smears contain many follicular cells without or scanty colloid in the background or when smears contain predominant population of Hurthle cells, the differential diagnosis would include hyperplastic adenomatoid nodule with Hurthle cell change, Hurthle cell adenoma, and Hurthle cell carcinoma.

Indeterminate smears: When smears containing cells with findings that were not clearly benign but were not diagnostic of a neoplasm or malignant lesions.

Suspicious for malignancy: Suspicious when aspirates suggest a follicular neoplasm, ie., hypercellular sample with scant colloid and a significant proportion of microfollicules, trabeculae, or crowded overlapping clusters of follicular cells (also includes lesions consisting of oncocytic [Hürthle cell] neoplasms).

\section{Malignant lesions}

a. Papillary Carcinoma

b. Medullary carcinoma

c. Anaplastic Carcinoma

d. Lymphoma

e. Metastatic

\section{Group B}

Was assigned to report with the following conventional system;

Cytological diagnosis was categorized into 5 categories:

Unsatisfactory Smears (Same as described in group) A

Benign or Negative for malignancy: This group included thyroid cysts, colloid goiters, thyroiditis and hyperplasia, benign when aspirates were hypo cellular to moderately cellular with moderate to abundant colloid and follicular cells with round nuclei of uniform size.

Follicular lesions: Aspirates of Follicular patterned lesions other than follicular variant of papillary carcinoma; (Aspirates of processes which cannot be fully classified by FNAC as they require histological assessment for actual classification).

Indeterminate: Aspirates showing some but not all features of malignancy, e.g., cell clusters with enlarged and grooved nuclei without true pseudo inclusions; and .The indeterminate group included follicular neoplasm's, Hurthle cell neoplasm's, and suspicious thyroid carcinoma.

Positive for malignancy: Any Malignant category.

\section{Group C}

Was assigned to report thyroid FNAC by the Bethesda System having the following six categories [14].

Nondiagnostic or Unsatisfactory: Cyst fluid only virtually a cellular specimen other (obscuring blood, clotting artifact, etc).

Benign: Consistent with a benign follicular nodule (includes adenomatoid nodule, colloid nodule, etc) Consistent with lymphocytic (Hashimoto) thyroiditis in the proper clinical context. Consistent with granulomatous (sub acute) thyroiditis others (Figure 1).

Atypical of Undetermined Significance (AUS) or Follicular Lesion of Undetermined Significance (FLUS) (Figures 2 and 3).

Follicular neoplasm or Suspicious for a follicular neoplasm Specify if Hürthle cell (oncocytic) type (Figure 3).

Suspicious for malignancy: Suspicious for papillary carcinoma, Suspicious for medullar carcinoma, Suspicious for metastatic carcinoma, Suspicious for lymphoma (Figure 4).

Malignant: Papillary thyroid carcinoma, Poorly differentiated carcinoma, Medullar thyroid carcinoma, Undifferentiated (anaplastic) 
carcinoma, Squamous cell carcinoma, Carcinoma with mixed features (specify), Metastatic carcinoma, Non-Hodgkin lymphoma or others (Figure 4).

The cases were operated and evaluated for histopathological changes

Histopathological diagnoses of patients who had undergone surgery were used as the gold standard for correlation with the cytological interpretations. In the event where more than one nodule underwent biopsy on the same patient, the most abnormal FNA result was used for analysis. The specimens with discrepant cytological and histological

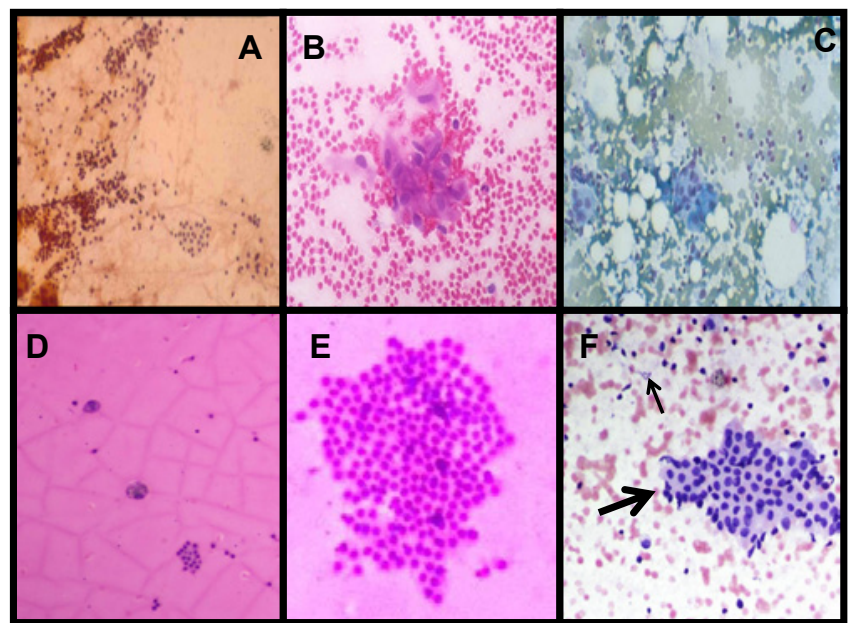

Figure 1: Microscopy of The Bethesda System for reporting Thyroid Cytopathology (TBSRTC) Class II smear (Benign lesions) A; Normal Cytology (Pap Stain 20x), B;Granulomatous Thyroiditis (40x H\&E), C; Hashiomotos thyroiditis (Pap Stain 20x), D; Cystic aspirate (H\&E Stain 20x), E; Colloid goiter with Abundant Colloid material (H\&E Stain 20x), F: Lymphocytic thyroiditis (Few Follicular cells, epitheliod like cells (Thick arrow) against lymphocytes (Thin arrow H\&E stain 20x).

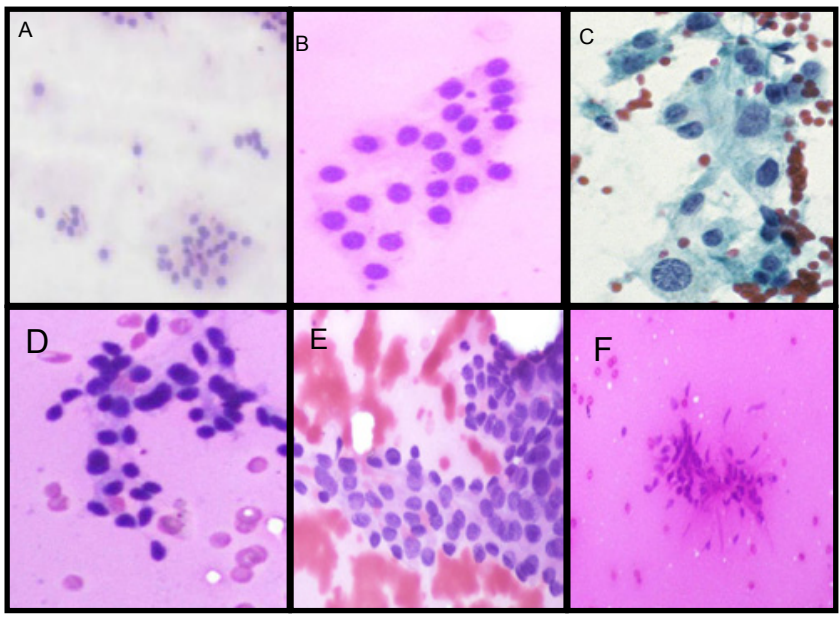

Figure 2: Microscopy of The Bethesda System for reporting Thyroid Cytopathology (TBSRTC) Class III: AUS/FLUS: A:Sparsely cellular specimen comprised predominantly of microfollicles, $B$ : Most of the specimen is comprised of benign macrofollicles (H\&E stain 20x) C:Atypical cells post radioiodine therapy (Pap stain 40x), D: Follicular cells with crowding and pseudostratification, (40x H\&E Stain)E:Rare groups show nuclear grooves and nuclear profile irregularity (H\&E stain 40x), F:Numerous non-cohesive spindle cells of uncertain significance (H\&E Stain 40x).

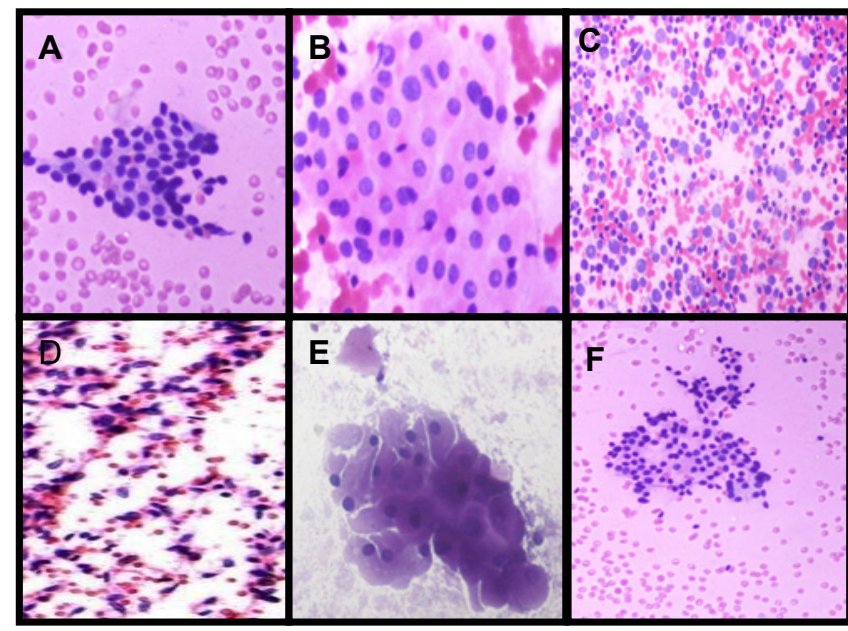

Figure 3: Microphotographs of Class IV Atypica of Undetermined Significance (AUS) or Follicular Lesion of Undetermined Significance (FLUS), A: Follicular cells with crowding and pseudostratification (H\&E 20x), $\mathrm{B}$ :Hurthle cells in sheets and colloid materials, C: Hurthle cells with atypical lymphocytes, D:Atypical cyst lining cells, E:Class IV smears showing (H\&E 40x)Hurthle cell lesions with scanty colloid material, F: Follicular Lesions with scanty colloid material,

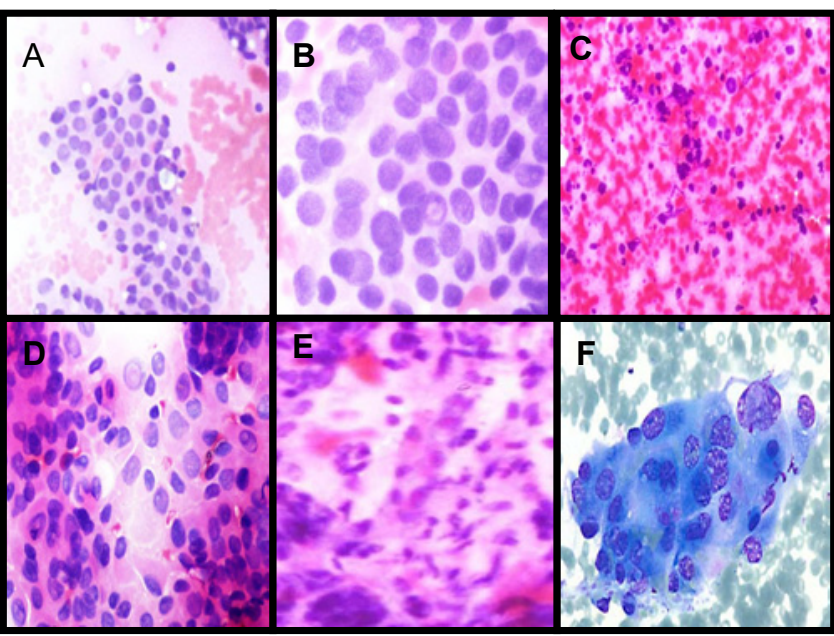

Figure 4: Microphotograph of $A$ and $B(20 x$ H\&E) Suspicious smear of class $\mathrm{V}$ with one or two features of Papillary carcinoma, TBSRTC class VI (Malignant) smears C (5x H\&E): Showing features of Lymphoma and D; Smears with all features of Papillary carcinoma (papiilary structure pattern, nuclear overlaping, nuclear grooving, psudonuclear inclusions, and smudged nuclear chromatins) E: Medullary Carcinoma (Medullary carcinoma showing in FNA loosely clustered spindle- shaped tumor cells with scanty, ill-defined cytoplasm (Pap stain, $\times$ 400).), D; Anaplsatic carcinoma with lager nuclei and anaplasia,

diagnoses were reviewed to determine the plausible explanations of these discrepancies.

\section{Statistical analysis}

The sensitivity, specificity and diagnostic accuracy were calculated considering thyroid FNA as a 'screening test'; FNA specimens interpreted as benign were considered to be true negative samples and the remaining categories were considered to be true-positive samples because they led to a recommendation of surgery. The false-positive category included cases that were diagnosed as follicular and malignant 
but which were confirmed as benign on histopathological evaluation. The false-negative cases included those diagnosed as benign on FNA but confirmed as malignant upon surgical excision.

\section{Results}

Of the 120 specimens 13 samples (10.8\%) were unsatisfactory for diagnosis as evaluated by the three groups. In Group A the old system was adopted where cytological categories were made as Colloid Goiter, Colloid cyst, Thyroiditis, Follicular/ Lesions Neoplasm, Indeterminate, Suspicious for Malignancy and frankly malignant smears. In this group false positive and false negative rate was much higher as compared to group B and C. The sensitivity and specificity was calculated as: Sensitivity: 77\% and Specificity: 69\% (Table 1 and 2).

In group B, only four categories were suggested like Unsatisfactory, negative for malignancy, Indeterminate and malignant smears. In this group false positive results improved to a certain extent but false negative results remained the same when compared with histopathology. The sensitivity was $85 \%$ and specificity was $65 \%$ (Table 3 and 4 ).

In group C latest system for evaluation of thyroid smears were performed which gave no false negative result with highest sensitivity, while false positive results also improved with higher specificity outcome as compared to the other two groups (Table 5 and 6 ).

When the sensitivities and specificity of two systems (Group A and B) were compared with the Bethesda Method (Group C), far better results were achieved (Table 7 ).

\section{Discussion}

Thyroid nodules are a common clinical problem and are noted much more frequently on imaging examinations than are apparent by palpation and clinical observation. Fine-Needle Aspiration Biopsy (FNAB), which yields a cytology specimen for analysis, is the standard test to determine whether surgical removal of a detected nodule is recommended or not. Fortunately, the vast majority of nodules are benign, but when they are discovered, an assessment regarding the need to exclude malignancy using FNA must be performed [14].

Various reporting systems for thyroid cytology have been adopted at our institution for the last three decades but none of them was related to the prognosis of disease and patients outcome[10,12]. These reporting schedules were least informative due to variability of sensitivity and least reproducibility. The introduction of new the simplified Bethesda Thyroid Reporting System into six categories logically relates to the prognosis of thyroid diseases and may increase the reproducibility of diagnosis [11].

\begin{tabular}{|l|c|c|c|c|}
\hline \multirow{2}{*}{$\begin{array}{l}\text { Group A } \\
\text { Lesions ( on FNA REPORTING) }\end{array}$} & \multirow{2}{*}{ Numbers } & \multicolumn{2}{|c|}{ Histopathology } & Total \\
\cline { 3 - 5 } & & Benign & Malignant & \\
\hline Non-diagnostic or Unsatisfactory & 13 & Excluded & Excluded & \\
\hline Colloid Goiter & 50 & 47 & 3 & 50 \\
\hline Colloid cyst & 16 & 16 & 0 & 16 \\
\hline Thyroiditis & 5 & 4 & 1 & 5 \\
\hline Follicular/ Lesions Neoplasm & 18 & 17 & 1 & 18 \\
\hline Indeterminate & 5 & 4 & 1 & 5 \\
\hline Suspicious for Malignancy & 5 & 2 & 3 & 5 \\
\hline Malignant Lesions & 8 & 0 & 8 & 8 \\
\hline Totals & 120 & 90 & 17 & 107 \\
\hline
\end{tabular}

Table 1: Distribution of different lesions diagnosed by groups $A$ of Histopathologists.

\begin{tabular}{|c|c|c|c|}
\hline & Cytopathology & Histopathology & Total \\
\hline FNAC +ve & 17 & 30 & 47 \\
\hline FNAC -VE & 05 & 68 & 73 \\
\hline Total & 22 & 98 & 120 \\
\hline
\end{tabular}

Sensitivity: $77 \%$; Specificity: $69 \%$, Positive predictive value:37\%, Negative predictive value $93 \%$

Table 2: Comparison of FNAC of Group A with histopathology.

\begin{tabular}{|c|c|c|c|c|}
\hline Group B & Numbers & \multicolumn{2}{|c|}{ Histopathology } & Total \\
\hline Lesions (FNA cytology) & & Nil & Nil & Excluded \\
\hline Unsatisfactory Smears & 13 & 66 & 3 & 90 \\
\hline Negative for malignancy & 69 & 18 & 2 & \\
\hline Follicular Lesions & 20 & 6 & 2 & 0 \\
\hline Indeterminate & 8 & 0 & 10 & 17 \\
\hline Malignant Lesions & 10 & 90 & 107 & 107 \\
\hline Totals & 120 & & \\
\hline
\end{tabular}

Table 3: Distribution of different lesions diagnosed by groups $B$ of Histopathologists.

\begin{tabular}{|c|c|c|c|}
\hline & Cytopathology & Histopathology & Total \\
\hline FNAC +ve & 17 & 35 & 52 \\
\hline FNAC -VE & 03 & 65 & 68 \\
\hline Total & 20 & 100 & 120 \\
\hline
\end{tabular}

Sensitivity: $85 \%$, Specificity: $65 \%$, Positive predictive value:32\%, Negative predictive value $95.5 \%$

Table 4: Comparison of FNAC of Group B with histopathology.

\begin{tabular}{|c|c|c|c|c|}
\hline \multirow{2}{*}{\multicolumn{2}{|c|}{ Group C CYTOPATHOLOGY }} & \multicolumn{2}{|c|}{ Histopathology } & \multirow{3}{*}{$\begin{array}{r}\text { Total } \\
13\end{array}$} \\
\hline & & \multirow{2}{*}{$\begin{array}{c}\text { Benign } \\
\text { NIL }\end{array}$} & \multirow{2}{*}{\begin{tabular}{|c} 
Malignant \\
NIL
\end{tabular}} & \\
\hline 1 & Non-diagnostic or Unsatisfactory & & & \\
\hline II & Benign & 72 & 0 & 72 \\
\hline III & $\begin{array}{l}\text { Follicular Neoplasm or Suspicious for a } \\
\text { Follicular Neoplasm }\end{array}$ & 14 & 1 & 15 \\
\hline IV & $\begin{array}{l}\text { Atypia of Undetermined Significance } \\
\text { or Follicular Lesion of Undetermined } \\
\text { Significance }\end{array}$ & 2 & 2 & 4 \\
\hline V & Suspicious for Malignancy & 2 & 3 & 5 \\
\hline $\mathrm{VI}$ & Malignant & 0 & 11 & 11 \\
\hline Total & & 90 & 107 & 120 \\
\hline
\end{tabular}

Table 5: Distribution of different lesions diagnosed by groups B of Histopathologists.

\begin{tabular}{|c|c|c|c|}
\hline & Cytopathology & Histopathology & Total \\
\hline FNAC +ve & 17 & 18 & 35 \\
\hline FNAC -VE & 0 & 85 & 85 \\
\hline Total & 17 & 103 & 120 \\
\hline
\end{tabular}

Sensitivity: $100 \%$, Specificity: $82.5 \%$, Positive predictive value:45\%, Negative predictive value $100 \%$

Table 6: Comparison of FNAC of Group C with histopathology.

FNAC of the thyroid is the key preoperative investigation of thyroid lesions. There are overlaps in the criteria for diagnosis of certain lesions, particularly important regarding those reported as follicular neoplasm's. Thyroid FNAC allows binary triaging for surgery, to enable a decision to operate or not, albeit with some subtleties as some cases may require re-aspiration or reassessment after a period of time. The reporting of thyroid FNAC, however, is in many cases not binary. Various diagnostic category systems for reporting FNAC have been reviewed recently by Dr Helen Wang $[15,16]$.

These data demonstrate that the recently introduced Bethesda classification system is excellent for reporting thyroid FNAs. Each 


\begin{tabular}{|c|c|c|c|}
\hline Categories & Sensitivity & Specificity & Significance values \\
\hline$A$ & 77 & 69 & \multirow{3}{*}{$\begin{array}{l}\text { Sensitivity of Group } B \text { and } C \text { is significantly higher } 0.051 \text { as compared to group } A(p=0.051 \\
\text { and } 0.000)^{\prime} \text { Sensitivity of } C \text { is also significantly high as compared to } B(p=0.000) \text { Specificity } \\
\text { of Group } B \text { is not significant }(0.326) \text { as compared to group } A \\
\text { Specificity of } C \text { is also significantly high as compared to } A \text { and } B(p=0.009 \text { and } 0.002)\end{array}$} \\
\hline B & 85 & 65 & \\
\hline C & 100 & 82.5 & \\
\hline
\end{tabular}

Note: While specificity of three groups is non significant $0.278,0.236$ and 0.316 respectively

Table 7: Comparison of Sensitivity and specificity of all systems Group A, B and C.

\begin{tabular}{|l|l|l|l|}
\hline Bethesda System & \multicolumn{2}{l|}{} & \multicolumn{2}{l|}{} \\
\hline Classes & Description & $\begin{array}{l}\text { Risk of malignancy } \\
\text { (Percentage) }\end{array}$ & Usual management \\
\hline I & Non-diagnostic or Unsatisfactory & $1-4$ & Repeat \\
\hline II & Benign & $0-3$ & Follow up \\
\hline III & Follicular Neoplasm or Suspicious for a Follicular Neoplasm & $5-15$ & surgical lobectomy \\
\hline IV & $\begin{array}{l}\text { Atypia of Undetermined Significance or Follicular Lesion of Undetermined } \\
\text { Significance }\end{array}$ & $15-30$ & surgical lobectomy \\
\hline V & Suspicious for Malignancy & $60-75$ & near-total thyroidectomy or surgical \\
\hline VI & Malignant & 100 & $\begin{array}{l}\text { near-total thyroidectomy or surgical } \\
\text { lobectomy }\end{array}$ \\
\hline
\end{tabular}

Table 8: Diagnostic categories, associated risk of malignancy and clinical management [20].

diagnostic category conveys specific risks of malignancy, which offers guidance for patient management [17].

We used different methods of reporting since 1990, and we tried to improve our reporting technique because we found that our surgeons had difficulty in understanding the complexities of our thyroid cytopathology reporting. We also understand that this problem may lead to difficulty in the management of patients with follicular neoplasm, follicular lesions etc. In Pakistan, Agha Khan University Hospital and Shaukat Khanum Research Centre have also developed their own in house reporting systems for thyroid FNAC $[12,18]$.

When we compared our different reporting systems, we concluded that the journey is still long to approach a final destination. The false positive reports were commoner in our previous two decades older techniques, where the screening tests show $77 \%$ sensitivity and $69 \%$ specificity. The older system did not help in the prognosis of disease and patients outcome especially in Follicular lesions.

We improved our system a decade back and results were published in medical journals. Our journey was to make it simple for the understanding of consultants to propose their line of management. A simplified reporting scheme would, undoubtedly, have to address the assessment of adequacy and an acceptable rate of inadequate diagnoses could then be determined [10]. At the present time there is no accepted definition of what constitutes an inadequate thyroid FNAC, or how cystic thyroid lesions should be classified. In the old system the false positive and false negative results were also higher as compared to the newly adopted Bethesda system. The sensitivity was $85 \%$ and specificity was $65 \%$ in Group B where the old system was adopted.

The vast array of diagnostic nomenclature currently in use can usually be made to fit into these systems and thus easily explained to clinicians. There is now a need for a more unified approach to the reporting of thyroid FNAC. This would allow for better assessment of how FNAC diagnoses relates to therapy and outcome and for the development of truly evidence-based treatment recommendations. In the newly adopted system we used the six tire technique based on Bethesda Reporting system for Thyroid Cytopathology. The reporting is based upon numbers or stepwise descriptions The Bethesda System for Reporting Thyroid Cytopathology is a standardized reporting system for classifying thyroid fine-needle aspiration results comprising of 6 diagnostic categories with unique risks of malignancy and recommendations for clinical management. like (I) Nondiagnostic (II) Benign (III) Aspirates of atypia/follicular lesion of undetermined significance (IV) Follicular neoplasm/suspicion for a follicular neoplasm (V) Suspiciously malignant aspirates and (VI) Malignant aspirates $[11-13,19]$. The sensitivity and negative predictive values proved to be $100 \%$ with no false positive results and high $(82.5 \%)$ specificity with low false negative values. The findings are consistent with the study of Wong et al. [19].

When results of these three systems were compared Bethesda adapted method was found to be more superior as compared to others. Sensitivity of Group B and C is significantly higher 0.051 as compared to group A ( $p=0.051$ and 0.000 )' Sensitivity of $C$ is also significantly high as compared to $B(p=0.000)$. Specificity of Group B is not significant (0.326) as compared to group A Specificity of $C$ is also significantly high as compared to $A$ and $B(p=0.009$ and 0.002 )- table 7. Our findings are consistent with others who also used this reporting system [13,17].

Use of Bethesda reporting system helps in the prognosis, management and patient's outcome and minimizes the unnecessary surgical procedures for thyroid swellings (Table 8) [20].

\section{Conclusion}

By Adapting the Bethesda Cytopathology Reporting system a high sensitivity and high negative predictive values can help to determine a better patient outcome due to proper clinical management of thyroid swellings.

\section{Problems experienced in description of Bethesda reporting systems and suggestions}

We experienced difficulty in reporting two categories of Bethesda system for thyroid cytopathology reporting namely Atypia of undetermined significance or follicular lesions of undetermined significance and Follicular Neoplasm or Suspicious for a Follicular Neoplasm specify if hurthle cell (oncocytic) type, therefore we suggest both classes should be submerged in one category and a new name should be proposed. This will reduce the false positive results if both categories are reported under one new class. Our suggestion is to name 
Citation: Bukhari MH, Khan AA, Niazi S, Arshad M, Akhtar ZM, et al. (2012) Better Thyroid Cytopathology Reporting System May Increase the Clinical Management and Patients Outcome. J Cytol Histol 3:158. doi:10.4172/2157-7099.1000158

Page 6 of 6

it as Atypica of undetermined Significance with Follicular Neoplasm. Both benign and malignant follicular lesions should be reported under this heading along with the hurthle cell lesions.

\section{References}

1. Gharib H, Goellner JR (1993) Fine-needle aspiration biopsy of the thyroid: an appraisal. Ann Intern Med 118: 282-289.

2. Ferraz C, Eszlinger M, Paschke R (2011) Current state and future perspective of molecular diagnosis of fine-needle aspiration biopsy of thyroid nodules. $J$ Clin Endocrinol Metab 96: 2016-2026.

3. Eze OP, Cai G, Baloch ZW, Khan A, Virk R, et al. (2012) Vanishing Thyroid Tumors: A Diagnostic Dilemma Following Ultrasound Guided Fine Needle Aspiration. Thyroid

4. Cappelli C, Pirola I, Gandossi E, De Martino E, Agosti B, et al. (2009) Fineneedle aspiration cytology of thyroid nodule: does the needle matter? South Med J 102: 498-501.

5. Moslavac S, Matesa N, Kusic Z (2010) Thyroid fine needle aspiration cytology in children and adolescents. Coll Antropol 34: 197-200.

6. Kelman AS, Rathan A, Leibowitz J, Burstein DE, Haber RS (2001) Thyroid cytology and the risk of malignancy in thyroid nodules: importance of nuclear atypia in indeterminate specimens. Thyroid 11: 271-277.

7. Lewis CM, Chang KP, Pitman M, Faquin WC, Randolph GW (2009) Thyroid fine-needle aspiration biopsy: variability in reporting. Thyroid 19: 717-723.

8. Anil G, Hegde A, Chong FH (2011) Thyroid nodules: risk stratification for malignancy with ultrasound and guided biopsy. Cancer Imaging 11: 209-223.

9. Borget I, Vielh P, Leboulleux S, Allyn M, lacobelli S, et al. (2008) Assessment of the cost of fine-needle aspiration cytology as a diagnostic tool in patients with thyroid nodules. Am J Clin Pathol 129: 763-771.

10. Bukhari MH, Niazi S, Hanif G, Qureshi SS, Munir M, et al. (2008) An updated audit of fine needle aspiration cytology procedure of solitary thyroid nodule. Diagn Cytopathol 36: 104-112.

11. Poller DN, Stelow EB, Yiangou C (2008) Thyroid FNAC cytology: can we do it better? Cytopathology 19: 4-10.

12. Basharat R, Bukhari MH, Saeed S, Hamid T (2011) Comparison of fine needle aspiration cytology and thyroid scan in solitary thyroid nodule. Patholog Res Int 2011: 754041.

13. Bongiovanni M, Spitale A, Faquin WC, Mazzucchelli L, Baloch ZW (2012) The Bethesda System for Reporting Thyroid Cytopathology: a meta-analysis. Acta Cytol 56: 333-339.

14. Langer JE, Baloch ZW, McGrath C, Loevner LA, Mandel SJ (2012) Thyroid nodule fine-needle aspiration. Semin Ultrasound CT MR 33: 158-165.

15. Wang $\mathrm{HH}$ (2006) Reporting thyroid fine-needle aspiration: literature review and a proposal. Diagn Cytopathol 34: 67-76.

16. Poller DN, Ibrahim AK, Cummings MH, Mikel JJ, Boote D, et al. (2000) Fineneedle aspiration of the thyroid. Cancer 90: 239-244.

17. Theoharis CG, Schofield KM, Hammers L, Udelsman R, Chhieng DC (2009) The Bethesda thyroid fine-needle aspiration classification system: year 1 at an academic institution. Thyroid 19: 1215-1223.

18. Mahar SA, Husain A, Islam N (2006) Fine needle aspiration cytology of thyroid nodule: diagnostic accuracy and pitfalls. J Ayub Med Coll Abbottabad 18: 2629.

19. Wong LQ, Baloch ZW (2012) Analysis of the bethesda system for reporting thyroid cytopathology and similar precursor thyroid cytopathology reporting schemes. Adv Anat Pathol 19: 313-319.

20. Cibas ES, Ali SZ, Conference NCITFSotS (2009) The Bethesda System For Reporting Thyroid Cytopathology. Am J Clin Pathol 132: 658-665. 